\title{
Paneles de impacto de justicia restaurativa como reparación y resocialización en homicidio*
}

\author{
Impact Panels on Restorative Justice as Reparation and \\ Resocialization in Homicide
}

\author{
Angela Tapias** \\ ORCID: 0000-0003-1131-6791 \\ Universidad Santo Tomás, Colombia \\ Recibido: 9 de julio de 2019 \\ Revisado: 5 de noviembre de 2019 \\ Aceptado: 30 de marzo de 2020
}

\section{Resumen}

La justicia restaurativa son acciones dirigidas a reparar el daño causado por la ofensa. Bajo este principio se aplicaron paneles de impacto a víctimas y ofensoras de homicidio, para evaluar su efecto y el cumplimiento de las reparaciones. Las cuatro ofensoras participaron voluntariamente, reconocieron el daño causado y padecido. Tres de ellas ofrecieron datos de ubicación de las víctimas, sin embargo, solo fue posible realizar un panel con una víctima de otro caso de homicidio. Los hallazgos indican que fue posible la realización de un diálogo reparador pacífico, se favoreció la mutua comprensión, todas las internas afirman no reincidir, ofrecen reparaciones simbólicas viables y cumplen parcialmente. Por su parte las víctimas manifiestan ausencia de miedo e intención de mantener un vínculo solidario con las internas. No obstante, se concluye cumplimiento parcial por parte de las ofensoras y poco compromiso institucional para apoyar el programa.

Palabras clave: justicia restaurativa, homicidio, panel de impacto, víctimas.

Artículo de investigación. Citar como: Tapias, A. (2020). Paneles de impacto de justicia restaurativa como reparación y resocialización en homicidio. Diversitas: Perspectivas en Psicología, 16(2), 427-439. https://doi.org/10.15332/22563067.6321

Autor de correspondencia: Angela Cristina Tapias. Universidad Santo Tomas, Bogotá, Colombia. Correo electrónico: angelatapias@usantotomas. edu.co 


\begin{abstract}
Restorative justice can be understood as actions to repair the damage caused by an offense. Under this principle, the impact panels were applied to victims and offenders of homicide, to assess their effect and the compliance with reparations. The four offenders participated voluntarily, acknowledging the damage caused and suffered. Three of them provided data on the location of the victims; however, it was only possible to conduct a panel with a victim from another homicide. The findings indicate that a peaceful reparative dialogue was possible, mutual understanding was fostered, and all inmates stated that they would not reoffend, offered viable symbolic reparations, and partially complied. Meanwhile, the victims demonstrated an absence of fear and an intention to maintain a bond of solidarity with the inmates. However, partial compliance by offenders and little institutional commitment to support the program are evidenced.
\end{abstract}

Keywords: restorative justice, homicide, panel impact, victims.

\section{Introducción}

Existe la política universal de promulgar la Justicia Restaurativa (JR en adelante). La Organización de las Naciones Unidas (onU, 1999) promueve el "Desarrollo e Implementación de Medidas de Mediación y JR en Justicia Criminal" y el Consejo Económico y Social (2002) aprobó los "Principios Básicos de la Utilización de Programas de JR en Materia Criminal”, ya que es un modelo que favorece la humanización del conflicto, devuelve el poder a las partes, desjudicializa los problemas y resulta más rápido y económico. Particularmente en Colombia el Comité Nacional de Política Social en el Conpes 3629 (2009), la Ley de Infancia y Adolescencia 1098 (2006) y el Código de Procedimiento Penal Ley 906 (2004) demandan su implementación.

La JR se fomenta debido a que surge como complemento y crítica al carácter represivo del derecho penal, el cual no ha bastado para restablecer la convivencia, por lo que diversos autores convocan al derecho penal retributivo a descentrarse del ofensor y concentrarse en la víctima y el daño que padeció (Braithwhite, 2001; Gilman, 2003; Zehr,1990 citados por Uprimny, Saffón, Botero y Restrepo, 2006) En la JR la prioridad para hacer justicia, es reparar el daño causado en lo individual, en lo relacional y lo social, lo que la convierte en un modelo que contrasta con la justicia penal tradicional centrada en la sanción.

Este paradigma de justicia es novedoso porque se enriquece de fuentes culturales, religiosas y éticas
(Minow, 1998 citado por Uprimny et al., 2006) Por sus características, las víctimas que participan en la JR obtienen mayor satisfacción, también es alta la voluntad de participación de los ofensores y durante el proceso ellos se involucran más emocionalmente, disminuyen las racionalizaciones y su nivel de reincidencia es menor (Comisión Europea, 2010).

La justicia restaurativa (JR) "Es un proceso que busca la reparación del daño a la víctima y la restauración del tejido social dañado con la conducta criminal, y junto con ello la rehabilitación del victimario, mediante el encuentro y el dialogo participativo, voluntario y activo entre cuatro actores: víctima, victimario, sociedad y Estado" (Echeverri y Maca, 2007, p.17). Van Ness (2007) citado por Vaandering (2011) resalta tres concepciones generales de la justicia restaurativa: el encuentro, la reparación y la transformación. También Vaandering (2011) lo caracteriza aclarando que es más una filosofía, un nuevo paradigma, que un grupo pragmático de técnicas. Sus principios son flexibles, aunque se compara con la justicia coercitiva, su esencia es la voluntariedad. Es decir, los participantes no se restringen solo a los sujetos directamente involucrados como en la mediación, sino que puede incluso involucrar actividades tales como conferencias con familias y comunidades. Se considera así un proceso y un resultado, ya que es clave para su culminación que se cumplan las reparaciones pactadas, pero la forma a través de la cual se llega a las acciones de reparación es la esencia del proceso. Esto último coincide con la postura de Doolin (2007) quien indica que los componentes procesal y residual son esenciales para que realmente se constituya en 
un programa restaurativo. En este proceso participan de forma activa la víctima, el delincuente y otros miembros de la comunidad afectados por el delito, para la resolución de cuestiones derivadas del delito, por lo general con la ayuda de un facilitador. Se considera que conlleva un resultado reparador porque comprende el acuerdo alcanzado al final de este proceso restaurativo, entre los que se pueden incluir la reparación, la restitución y el servicio a la comunidad, encaminados a atender a las necesidades y responsabilidades individuales y colectivas de las partes, así como lograr la reintegración de la víctima y el delincuente.

Estudios empíricos acerca de la efectividad de la JR expresan resultados positivos de su aplicación (Sherman y Strang 2007). En este sistema, quien causa el daño reconoce su responsabilidad con más frecuencia, disminuye la reincidencia, particularmente de delitos de violencia interpersonal, incrementa el bienestar de las víctimas, reduce el daño psicológico y la venganza, disminuye los tiempos de la resolución, los costes económicos de la justicia y la necesidad de sentencias de culpabilidad. En general ofensores y víctimas tras participar en la JR prefieren este tipo de proceso a la justicia retributiva tradicional.

Dentro de los métodos para la aplicación de la justicia restaurativa Bazemore y Umbreit (2001), explican cuatro: 1) la mediación víctima-ofensor, 2) las conferencias de grupos familiares, 3) los círculos de discusión o sentencia y 4) las mesas comunitarias de reparación. Umbreit, Vos, Coates, (2006) identifican y evalúan los métodos mencionados y los paneles de reparación que son los que se usaron en el presente estudio. Estos paneles son programas basados en la comunidad que invitan a las víctimas y los delincuentes a participar juntos en la elaboración de una respuesta adecuada a la ofensa, posteriormente la junta comunitaria presenta un informe al tribunal sobre el cumplimiento por parte del ofensor de las reparaciones pactadas (Umbreit et al., 2006).

Estos paneles han estado en uso en Estados Unidos desde 1920, principalmente con delincuentes adultos condenados por delitos menores y no violentos (Bazemore y Umbreit, 2005), también han sido llamados tableros de reparación o juntas de comunidad reparadora, son modelos localizados y existe poca información sobre ellos. En Vermont se han utilizado principalmente con los delincuentes adultos, pero más recientemente se ha aplicado a los adolescentes (Bazemore y Umbreit, 2005).

Dentro de esta metodología de panel se encuentran diversos tipos, por ejemplo, uno en que las víctimas vienen en grupos pequeños y pasan al frente a hablar de manera constructiva a un grupo mayor de ofensores sobre el impacto que han padecido por el delito, esto con el fin de sensibilizarlos y prevenir nuevas agresiones (de Programas de Justicia de Estados Unidos, 2012). Otra modalidad consiste en que quien pasa al frente es el ofensor, de manera individual y es escuchado por un grupo representativo de las víctimas y de la comunidad que son quienes dialogan con él y pactan las reparaciones requeridas. La última modalidad con afinidad a estos es el panel de reparación-prevención de ofensores, en los cuales las personas que cometen la falta, brindan su testimonio, esto a manera de reparación con víctimas y forma de prevención con potenciales agresores que posteriormente puedan involucrarse en el mismo delito (Tapias, 2015).

En la práctica por ejemplo, Bonta y colaboradores (1998, citados por Umbreit, Vos y Coates, 2006) evaluaron uno de estos programas de panel y encontraron que después de un año las tasas de reincidencia fueron significativamente menores para los participantes del programa que para los grupos de comparación. De lo anterior se desprende la pregunta: ¿Cuál es el efecto de paneles de impacto de justicia restaurativa en víctimas y ofensoras en casos de homicidio en Bogotá? Por lo cual se pretende implementar paneles de impacto de justicia restaurativa en víctimas y ofensoras del delito de homicidio y evaluar su efecto.

\section{Método}

La investigación se desarrolló desde un enfoque de investigación-acción, en el que se destaca el carácter preponderante de la acción, superando la brecha entre teoría y práctica. Esto con el fin de unir al investigador con el investigado, superando descripción objetiva y dirigiéndose hacia la intervención participante. Es un modelo ecológico flexible, orientado a los valores, implica un talante 
democrático, ya que se construye con una perspectiva comunitaria, que se basa en planear, actuar, ejecutar y reflexionar (Rodríguez, Gil y García, 1999). Es una búsqueda autoreflexiva, llevada a cabo por participantes en situaciones sociales, para perfeccionar la lógica y la equidad (Kemis 1988 citado por Rodríguez et al., 1999). Dentro de los principios éticos seguidos por la investigación, se tuvieron el consentimiento informado, la voluntariedad, la acción sin daño y la confidencialidad.

\section{Participantes}

Todas las participantes fueron mujeres adultas $(n=5)$ que aceptaron voluntariamente el programa de justicia restaurativa. Una víctima (34 años) cuyo esposo fue asesinado por su labor recuperando habitantes de calle. Adicionalmente, cuatro mujeres condenadas por homicidio que se encontraban en un centro de reclusión de mujeres de Bogotá, todas madres cabeza de familia, dos de ellas asesinaron a sus compañeros sentimentales en medio de una riña y bajo el consumo de sustancias. La primera de ellas (26 años) presentó historia de ser abandonada por sus progenitores a los 13 años y habitar en la calle, presentaba trastorno de uso de sustancias psicoactivas y se dedicaba al trabajo sexual. La segunda (35 años) creció en un ambiente marginal, fue maltratada por sus padres, violada y padeció violencia de pareja. La tercera mujer (34 años) fue autora intelectual del homicidio de la amante de su tío y había crecido en un ambiente de mineros esmeralderos con armas, escoltas, en el que se normalizan acciones violentas. La cuarta interna (39 años) iba con la intención de robar, en el transcurso del crimen la víctima desconocida murió accidentalmente por asfixia pues estaba amordazada.

Inicialmente se proyectó contar con las víctimas directamente afectadas por estos casos, lastimosamente esto no fue posible, pues solo se logró ubicar a dos familias.

\section{Técnica de recolección de información}

Todas las narrativas fueron extraídas de entrevistas individuales, entrevistas grupales, talleres, y luego fueron sometidas a triangulación de la información. Se entendió por entrevistas a las interacciones sociales, entre las participantes y el investigador, gracias a las cuales se generaron significados (Rodríguez, Gil y García, 1999).

\section{Procedimiento}

El estudio estuvo conformado por tres fases: La primera fase fue de preparación y selección de las víctimas y las ofensoras, convocarlas, explicarles los beneficios del programa restaurativo, escuchar sus historias, contener su dolor y prepararlas para un diálogo constructivo. En esta fase se buscó a las familias víctimas de homicidio de cada uno de los casos de las cuatro condenadas y también de otro caso indirecto pero bajo el mismo delito, como forma intermedia para preparar al encuentro con las familias directamente afectadas del caso.

Con las familias ubicadas se realizó un contacto progresivo, primero se envió una carta institucional, luego se realizaron llamadas telefónicas y por último se realizó una reunión con la investigadora para conocer su historia acerca de la pérdida del familiar y entregar las cartas manuscritas realizadas por las internas. Finalmente, con las familias de los casos donde estaban directamente implicadas las mujeres condenadas, no se pudo realizar con las familias directamente víctimas de las homicidas implicadas, se realizó solo con una víctima que no es la que directamente ellas habían atacado, sino que fue víctima de homicidas desconocidos.

La segunda fase fue el encuentro restaurativo que representó la parte central de la investigación, de la cual se obtuvieron también narrativas y se desprendieron los acuerdos. Este encuentro se realizó en las instalaciones de reclusión.

Finalmente, la fase de cumplimiento de las reparaciones y evaluación, etapa en que la investigadora medió las entregas de lo pactado y recopiló las opiniones de las participantes. Esta etapa coincidió con la fase analítica, en la cual se dio una reducción de los datos, disposición y transformación de los mismos, obtención de resultados y conclusiones (Rodríguez et al., 1999).

Todo el estudio se llevó a cabo durante 18 meses, incluyendo el tiempo de gestiones institucionales (cuatro meses), aunque se priorizó el abordaje a la 
víctima del mismo delito empero de otro caso (tres sesiones), la mayor parte del tiempo se tuvo que dedicar a la preparación de las ofensoras (catorce sesiones), el encuentro restaurativo implicó una sesión única y la fase de cumplimiento se realizó con intermediación de la facilitadora (cuatro sesiones).

\section{Resultados y Discusión}

El análisis de los datos y las fuentes trianguladas permitió identificar categorías de significado, conservando los requisitos de exhaustividad, exclusión mutua y único principio clasificatorio que constituyen los enunciados en este apartado.

\section{Víctimas de los casos directos en fase preparación}

En ellas se encontraron básicamente dos actitudes favorables hacia el intercambio con la persona responsable y actitudes negativas:

\section{Actitudes favorables hacia el intercambio con las ofensoras}

"la sentencia si me parece justa...pero ahora me parece muy dura y me da pesar con los hijos", "yo tengo en el alma que si no perdono a esa señora, mi hermano (fallecido) no va a descansar", "a mí me gustaría, pero ando tan ocupada...y a mi papá también porque él ha sufrido otras muertes y yo creo que eso lo ayudaría, pero tocaría que fuera a la casa porque él es enfermito", "nosotros si quisiéramos participar, pero con un video o cartas...es difícil ir hasta la cárcel porque mi papá es minusválido".

Como se observa en los fragmentos, las personas consideran que el diálogo puede ser una forma de continuar la superación del trauma, lo que se complementa con las reflexiones de Sampedro (2010) quien cita la rehumanización como la tarea pendiente de la justicia, a fin de que el proceso judicial pase a ser un escenario para el encuentro víctima-victimario, un espacio para el testimonio que enlace creativamente la experiencia pasada y la presente, proyectándola hacia el futuro para que el pasado no quede en el olvido.

\section{Actitudes negativas hacia el intercambio con las ofensoras}

"la rabia que yo le tengo a esa familia", "usted fue contratada por ella? Esto le va a servir para el proceso de ella (mujer condenada)?”, “yo como mamá no quiero saber nada de eso, de pronto mis hijos si participen"

Se encontró que despues del paso de los años, aun persisten sentimientos de ira, escepticismo, desinterés por cualquier contacto. Estos sentimientos negativos son comprensibles, pues el duelo es más complejo en casos de muerte violenta (Sanz, 2019) y sus posturas de alejamiento de las ofensoras resultan lógicas. Como la participación voluntaria es fundamental en la justicia restaurativa oNU (2006) es respetable esta postura.

\section{Víctima de otro caso en fase de preparación}

\section{Expresiones que denotan aún el duelo}

"es un vacío que nadie va a llenar", "muy duro uno sentir la impotencia", "aún lloro mucho, lo extraño, especialmente los domingos que era el día en que compartíamos". Esto es esperable ya que tan solo han pasado 14 meses luego del deceso; según Espinosa y Tapias (2013) la pérdida del ser querido habitualmente genera un duelo que dura entre 6 meses y 1 año, empero la causa violenta de la muerte genera sentimientos de rabia, protesta y tendencia a negar el hecho, impotencia ante la impunidad, lo cual puede complicar y prolongar el duelo.

\section{Inclinaciones favorables hacia el intercambio con personas responsables}

"si quiero participar, todo lo que me ayude a superar esto", "si yo siempre he querido entrar a una cárcel y ver cómo es eso"

Se infiere que hay dos elementos que motivan a la víctima al acercamiento, el deseo de hablar de lo sucedido para elaborarlo y la curiosidad. Esto coincide en parte con lo referenciado por la literatura. 
Así, Umbreit y colaboradores (2006) reportan que las víctimas consideran que es buena idea participar para escuchar las explicaciones del ofensor, recibir una restitución, para compartir su dolor o ayudar al cambio del ofensor.

\section{Víctima de homicidio de otro caso durante el panel restaurativo}

\section{Relato sobre el homicidio}

"el me dio un pico y ... yo digo que ese fue su beso de despedida porque ahí fue cuando lo impactaron", "yo escuché dos balazos, aunque la fiscalía dijo que le habían dado tres impactos", "Cuando sonaron los disparos, yo salí y nos mostraron el revólver y nos devolvimos...pero yo pensé que habían entrado a agredirlo a él, pero no me había dado cuenta lo de Javier, lo veo en el piso y le digo Javier que pasó levántese, entonces yo fui a levantarlo y cuando me di cuenta mis manos estaban llenas de sangre y grité a mi mamá y le dije lo mataron", "uno queda con esas imágenes ahí", "para mí era difícil ver una moto", "yo siempre he sido miedosa y ahí sí que fue peor", "teníamos muchos proyectos a futuro".

Estos relatos denotan experiencias, duelo, alteración al proyecto de vida, miedo, todo lo cual configura daño psicológico (Espinosa y Tapias, 2013).

\section{Narrativas relacionadas a la comprensión de nuevas realidades}

"a él lo mataron por su labor social", "se hizo una marcha al cementerio, lanzamos globos, hubieron (sic) noticieros...no imaginé que tenía a mi lado una persona tan importante"," "yo no pensé que esto me fuera a pasar a mí lo que pasa en este país, que la intolerancia tocara las puerta de mi casa"

La víctima comprende que su caso es uno más de los que encaja en la realidad violenta de Colombia, al tiempo que dimensiona el papel sociopolítico que ejercía su compañero y lo hizo blanco de la criminalidad organizada.

\section{Solicitud de reparación}

"yo quisiera (como forma de reparación) una obra musical, porque él era músico o una tela recordando su historia". En esta petición se develan otras necesidades de las víctimas, ella requiere apoyo de otras personas para homenajear la memoria de su ser querido, se observa como las necesidades psicológicas y gestos simbólicos imperan sobre lo pragmático.

Según Cerruti (2009), el papel activo de la víctima es clave, ya que implica una de las buenas prácticas de acompañamiento psicojurídico según la Corporación AVRE (2009). En el panel de impacto, la víctima tiene la oportunidad de confrontar a las ofensoras con su propio dolor y adicionalmente solicitar las reparaciones que considera adecuadas para atender sus afectaciones subjetivas. En este caso que se solicitan acciones simbólicas de reparación, y se consideran estas acciones como aliada de la memoria con el objeto de dignificar a las víctimas y recordar los sueños por los cuales fueron asesinadas (Movimiento Nacional de Víctimas de Crímenes de Estado, 2010)

\section{Víctima de homicidio de otro caso posterior al encuentro}

"Gracias a ustedes, ojalá nos volvamos a encontrar", "Fue bonito conocerlas. Me gusto ir a la cárcel uno piensa que todo es peor y al conocerlas ve que no", "Es importante conocer a las chicas que están acá, da pesar con sus historias", "yo quisiera volver a visitarlas y llevarles un detallito", "Se nota que tienen buena intención".

Expresiones de afecto positivo e intención de generar un vínculo, en las que se resalta la ausencia de miedo. El miedo al delito es "una respuesta emocional caracterizada por un sentimiento de ansiedad y peligro ante la posibilidad de sufrir una lesión física o la pérdida de cualquier propiedad personal" (Berenguer 1990 citada por Ruiz, 2014, p.77) y en este caso se observó como la víctima apartándose del miedo, tiende a la cercanía con las internas, lo que se puede interpretar como disminución del miedo hacia el delito y las delincuentes. Al 
disminuir el miedo al delito, las víctimas disminuyen conductas de evitación y protección, deteriorando el tejido social y asumiendo riesgos para la salud (Ruiz, 2014).

Al realizar el seguimiento con la víctima, ella evaluó positivamente el proceso restaurativo pero señaló las deficiencias de la justicia retributiva "lo que más me duele es la impunidad que cerraron el caso porque el proceso no se movía y no había pruebas nuevas". Esta frase ilustra lo que la Corporación AVRE (2009) señala como efectos de la impunidad: afectación a la dignidad de la víctima, su sentido de identidad, frustración de su necesidad moral, de castigo a los responsables por medio de la justicia. Es importante aludir a la complementariedad con la justicia retributiva, ya que la JR no pretende abolir la justicia ordinaria. Zher (2006) aclara que la JR no es una panacea, ni un sustituto del sistema legal, pero sí son modelos que podrían potenciarse mutuamente.

\section{Ofensoras}

\section{Fase preparación}

"muy duro aceptar la realidad porque nunca lo planee", "a veces yo quisiera llorar y gritar me da cargo de conciencia", "hasta en sueños tenía mi pecado", "es la persona que yo amaba, amo todavía" Expresiones que denotan la aflicción generada por el delito cometido y por la privación de libertad.

\section{Actitudes de arrepentimiento, verguienza y cambio de actitud}

"Quiero pedir perdón, no me creo inocente”, “Mi Dios me trajo aquí para que yo reflexionara, una amiga me dijo que aterrada con mi cambio", "él ya me había apuñaleado...pero ahora pienso uno no es Dios para cegar la vida de nadie", "Mi mamá me contó que donde trabajaba le hablaban muy mal de mí, sin saber que era la hija, que drogadicta, loca había matado, que pena eso, que triste para mi mamá", "estoy muy marcada por lo que hice, porque fue algo muy grave", "triste me siento demasiado culpable y eso le dije al juez". Adicionalmente tres de las ofensoras mencionan en sus expectativas del programa el perdón y la cuarta menciona acercamiento y un poco de tranquilidad.

La experimentación de vergüenza, arrepentimiento y el ofrecimiento de disculpas son favorables para la transformación psicológica. Según Mockus 2002 y Fruchart y colaboradores (citados por López, Pineda y Mullet, 2014), el agresor al solicitar el perdón se somete a la eventualidad de ser o no perdonado, su ofrecimiento sincero de disculpas y el esclarecimiento de la verdad de los hechos facilitan el perdón. No obstante, se desea precisar que la JR se centra en la reparación, no es un programa orientado al perdón o la reconciliación, aunque esto pueda surgir espontáneamente dentro del proceso, depende enteramente de las partes (Zher, 2006).

\section{Factores que influyeron en la comisión del ilícito}

"En la casa por todo nos pegaban...me volví agresiva, en la calle me peleaba con cualquiera", "paso tal vez porque queremos tomar justicia por nuestras propias manos...acciones equivocadas", "Yo lo hice y no sé por qué paso...tal vez por el ambiente en que crecí...no sabía lo que estaba haciendo...yo no sentía miedo...no sé en qué momento tomé esa decisión", "Nosotras actuamos como queremos y no pensamos en otros que dañamos...cuidamos a los que amamos e ignoramos a otros que son amados por sus familias", "Hubiera sido él o yo...le doy gracias a Dios porque esto pasó porque así salí del vicio".

Se observaron realidades en torno a los factores de riesgo hacia el delito y así mismo dificultades para asumir la responsabilidad del daño causado, lo cual es usual en quienes cometen trasgresiones de acuerdo con Wachtel y O'Connell (citados por Vaandering, 2011), sucede frecuentemente que no asumen la responsabilidad de sus acciones y las racionalizan.

\section{Estigmatización}

"Ellos me ven como una persona criminal", "somos señaladas por una sociedad", "estamos prácticamente muertas para el resto de la sociedad". 
Expresiones de las que se infiere que la pena privativa de libertad es desintegradora y paradójica (Acosta, 2014), dando así más razones para aplicar la justicia restaurativa.

Estas actitudes negativas hacia los delincuentes confirman las halladas por Martín y Rodríguez (1990, citados por Ruiz, 2014) que reportan en grupos de profesionales y de control perciben a los delincuentes como "peligrosos", "marginados", "malas compañías", "irresponsables”, "inadaptados", "violentos" y "sin cultura"; contrastando con las del grupo de delincuentes que eligieron adjetivos como "buenos compañeros", "de buenos sentimientos", "van a lo suyo". Empero, en esta investigación las mujeres ofensoras asumieron actitudes similares a las del grupo de no delincuentes, lo que permite suponer que son menos permisivas hacia el delito.

\section{Ideación de muerte}

"Yo también me iba a cortar cuando lo vi muerto"... "esto -la cárcel- es un cementerio de vivos", "Yo me quise matar acá tomando varsol...yo pensé en matarme y acabar con todo", "Yo me quería cortar las venas y pensé que amanecería en la Unidad de Tratamiento y ahí me metieron a trabajar en aseo"

Estas frases provienen de las dos mujeres que asesinaron a sus compañeros sentimentales, de su ideación suicida se infiere la falta de sentido vital y un fuerte impacto emocional por la pérdida que a sí mismas se causaron.

\section{Impacto en las relaciones con los hijos}

Dos de las ofensoras que han dado a conocer a sus hijos la realidad de su situación afirman: "No me quieren, no me vienen a visitar", "creo que está consumiendo marihuana", "triste porque es toda una vida, tengo hijos, no les pude dar mejores oportunidades, mi hijo se refugia en el alcohol". De forma que se evidencia la ruptura de relaciones que ha generado el delito y dificultades en la salud mental de los sucesores.

Las otras dos internas mienten a sus hijos pequeños para proteger su imagen: "Mis hijos piensan que yo estoy en un colegio...y yo sé que estoy creando un muro", "Mi hijo me pregunta que cuando voy a salir y yo le digo que ya casi..." Este hijo tiene 9 años y padece encopresis. Aunque ambas prevén lo negativo de la irrealidad que les plantean a sus hijos, no tienen la capacidad de decirles la verdad y anticipan que esto genera secuelas.

\section{Reconocimiento del daño causado a las víctimas}

A medida que avanzan las sesiones y la confianza en el proceso, las internas lograron identificar y expresar los daños causados: "Lo que he llorado pensando en lo que esa niña ha sufrido creciendo sin su mamá. Yo no quiero hacer más daño", "El dolor y la tristeza que les causé a esa familia", "llena de preguntas, dudas, culpas, miedos y con muchos más arrepentimientos", "quiero que sepa que no pretendo beneficio legal", "en busca de su perdón", "perdón de corazón, solo pido a Dios que un día me puedan perdonar"... nueve referencias a la palabra perdón en 3 páginas. "yo no pido que me perdonen de un día para otro, pero yo también estoy sufriendo"

Estas anotaciones provienen de todas las ofensoras, es decir, que todas en mayor o menor grado y en diversos momentos expresan espontáneamente sus sentimientos, remordimientos y deseos de ser perdonadas. El reconocimiento del daño es un elemento crucial en la justicia restaurativa, no así el perdón, dado que no es un objetivo en este paradigma, aunque puede fluir de forma espontánea (Zher, 2012). En la JR se necesita que los agresores se hagan responsables de su comportamiento, que no racionalicen, ni eviten reconocer lo dañino de su actuar.

\section{Durante el encuentro}

"Gracias por venir, espero ser escuchada", "me siento muy contenta de que estén acá escuchando nuestras historias", "a la señora muchas gracias por las palabras de aliento, que fuerte nos hace sus palabras aquí, demostrando que somos diferentes, no como los demás piensan", "la mayoría gente que viene acá lo mira a uno como unas criminales, si, 
entonces uno se siente bien de que una persona lo trate así y lo mire a uno con cariño"

Estas expresiones dan cuenta del tono positivo del encuentro y la concreción de un clima social constructivo y de aceptación. Esto permite contrastar la estigmatización que implica el confinamiento en prisión. La prisión está estructurada para deshumanizar (Zher, 2012) que se contrarresta con lo que sugiere Acosta (2014), en tanto que la valoración humana es un "proceso que termina siendo un acto de conciencia, equivalente a un acto de cambio, asombro personal o suceso que determina un nuevo proceso en el interior" (p. 124).

\section{Expresiones sobre los hechos del homicidio}

"Cuando yo la vi, supe que estaba muerta porque yo crecí en el cartucho (zona de tolerancia) y ahí había visto muertos", "no sé cómo la mató, la persona que se quedó con ella...pero yo asumo la responsabilidad de haber estado ahí", "no fui lo suficientemente valiente para ayudar a la señora, me llené de miedo y ya estaba involucrada", "yo voy a contar mi historia, aunque es difícil, pero me ayuda a descansar el alma", "yo pensé darle un puntazo para asustarlo, más nunca pensé arrebatarle la vida", "esa sangre me cae en la cara en el cuerpo y se cae encima de mí y yo trato de auxiliarlo porque no era mi intención... yo vi que se me estaba yendo y le dije que me perdonara que yo lo amaba mucho...él se me fue", "yo decía llame a la policía a la ambulancia”, "yo nunca había tenido problemas con la ley", "yo todavía lo quiero muchísimo, lo amo muchísimo", "eso pasó hace como cuatro años, pero para mí es como si hubiera sido ayer, porque eso me marca muchísimo"

Al identificar estas frases, es evidente que ellas aceptan su involucramiento en los hechos, al tiempo que señalan el impacto en su propia psique, pues no tenían historial de conducta violenta, se aprecia como lo sucedido las excedió, empero aceptan su responsabilidad. El abordaje de estos temas tan humanos es propio de la JR, ya que a los agresores rara vez se les permite ver los verdaderos costos humanos de lo que han hecho (Zher, 2012).

\section{Intención de reparación}

"Quisiera disculparme con la mamá y brindarle una ayuda económica” , "Yo quisiera ayudar a atenderle las necesidades de la hija que ya es adulta, algo oportuno", "Yo haría todo lo que puedo, pero dinero no tengo...si esa persona está enferma yo daría un riñón...(órganos, huesos), sembrar un árbol y cuidarlo con una placa con el nombre", "lo reparamos pero no va a quedar igual, le faltan fragmentos por dentro, por dentro quedó lastimado y no se puede hacer nada", "podemos reparar con palabras, con actitudes, con ayuda económica", "no existe nada sobre la tierra que no hiciera", "compraría un árbol y lo cuidaría y pondría una placa con el nombre", "si pudiera curar en parte haría todo lo necesario tanto que le daría hasta mi vida", "yo quisiera volver a que fuéramos como antes...pero la familia de él me ve como una criminal...habíamos estudiado juntos en el barrio", "una de las ideas era escribirle, otra las manualidades que se trabajan acá”, "a mí me gustaría obsequiarle un joyerito...pero si le llama la atención algo en especial yo con mucho gusto la hago y se la obsequio".

Se puede observar la multiplicidad de ideas e intenciones de resarcir el daño causado, varias de estas reparaciones fueron pensadas para las víctimas del caso propio y otras se compartieron para la víctima del mismo delito pero de otro caso. Finalmente, pactaron para la víctima presente en el panel cuatro elementos representativos: una planta, una tela alegórica a la historia de su esposo asesinado, el cofre de madera y un dibujo. Con esto se aprecia el énfasis que las medidas de reparación simbólicas están orientadas a rescatar el recuerdo y la memoria de las víctimas, versan sobre el sentido, dan a conocer los hechos y el valor de las víctimas, su valor esta supeditado al proceso personal y colectivo, un esfuerzo por extraer una lección moral, un llamado de atención sobre la prevención moral (Beristain, 2008).

De estos elementos se cumplieron los dos primeros, ya que el cofre y el dibujo se imposibilitaron porque las internas encargadas fueron trasladadas de ciudad y se perdió toda comunicación. 


\section{Ofensoras posterior al encuentro}

\section{Experiencias positivas}

Tras las acciones reparadoras se conversó con las dos internas participantes que quedan en la reclusión y afirman: "aprendí a pensar antes de hacer, a caminar antes de correr", "el perdón es la liberación más grande", "yo le perdí miedo a las víctimas" por escrito confirman si desearon participar del programa restaurativo, recibir la preparación adecuada.

Según la percepción de las internas el proceso restaurativo en términos generales fue adecuado y retroalimentaron elementos sobre la previsión de consecuencias y de liberación de emociones negativas. Restaurar el daño, exige volver la mirada al otro, a las víctimas y a los victimarios, como protagonistas indispensables de una relación ética, una relación de compasión y responsabilidad, en la que me acogen mutuamente (Sampedro, 2010).

\section{Deseos para la víctima que asistió al panel}

“ojalá (la víctima) encuentre el amor y sea feliz, porque el amor es una estación”, "(la víctima) es una mujer fuerte, le digo que ánimo, adelante y es un tiempo suficiente para darse una oportunidad" Estos textos dan cuenta que las internas desean motivar a la víctima que asistió para que tenga esperanzas y rehaga su vida sentimental.

\section{Proceso inconcluso}

Agrega la interna que no dio los datos de su víctima: "yo siento que a mí me faltó, porque para mí no ha terminado porque no me encontré con la víctima, no he hecho por encontrarla", "vi el video (del encuentro) y lloré mucho", "a mí me faltó tiempo".

Con esto se aprecian las diferencias individuales, pues esta mujer dejó que transcurrieran meses para entregar los datos y abordar la familia perjudicada por su caso, a lo cual reacciona solo al final indicando que le faltó tiempo, es decir, que sigue considerando un locus de control externo las pocas posibilidades. Tambien se muestra que no asume su responsabilidad al dejar pasar el tiempo, es decir, continua con dificultades de afrontamiento y usa la evitación emocional, la cual es definida por Londoño y colaboradores (2006) como la movilización de recursos enfocados a ocultar o inhibir las propias emociones, evitar las reacciones emocionales valoradas por el individuo como negativas por la carga emocional, por las consecuencias o por la creencia de una desaprobación social si se expresa. Pese a que el programa ofrecía apoyos para el afrontamiento se requería la iniciativa de la víctima para superar su afrontamiento habitual.

\section{Realidades de prisión}

"no podemos hablar delante del personal de la institución", "Seguimos en un ambiente muy difícil, hoy nos tocó mentir para estar acá, vimos que chuzaron a una mujer"

Lamentablemente muchas de las realidades de prisión dificultan la transformación positiva y se convierten en un ambiente hostil y nocivo. Acosta (2014) afirma que la cárcel no es una forma de vida normal, tiene efectos desocializadores propios de la cultura carcelaria, es antifuncional como ente resocializador y se postula como violadora de derechos humanos, por lo cual propone un modelo que contraste enfocado a la integración social, a valorarse a sí mismo y a los demás, a recrearse y a pactar, principios muy cercanos a las propuestas restaurativas.

\section{Conclusiones}

Las participantes voluntariamente aceptaron la preparación para el panel restaurativo, no obstante las ofensoras requirieron mayor número de sesiones que las víctimas.

En las víctimas, se encontró que persiste el daño psicológico, por lo cual, algunas víctimas rechazaron y otras aceptaron participar del programa restaurativo, esto no fue obstáculo para realizar el panel de impacto con la víctima de homicidio de un caso distinto al de las mujeres condenadas, en el cual se planteó la solicitud de reparaciones eminentemente simbólicas, las cuales la víctima recibió con agradecimiento, y expresó que no persistía 
miedo hacia ellas y su disposición para volver a comunicarse con las ofensoras.

Todas las ofensoras condenadas manifestaron actitudes restaurativas, reconocimiento de responsabilidad del delito, arrepentimiento, presentaron disculpas y manifestaron el deseo de ofrecer diversas formas de reparación como disculpas, dinero, arte, trabajo, donación de órganos, plantas, artesanías, entre otras. Todas afirman no volver a hacer lo sucedido, evadir los riesgos (alcohol, drogas, malas compañías, entre otras) y tras el panel restaurativo valoraron positivamente el encuentro de forma generalizada.

Sin embargo, persiste en ellas la aflicción personal y familiar, ideas de muerte, estigmatización, identificación del daño propio, aunque también lograron identificar el daño causado a las víctimas. Tres de las cuatro internas brindaron datos para ubicar a sus víctimas y solo dos de ellas realizaron cartas para iniciar la comunicación con las víctimas, lo cual indica limitaciones personales para asumir completamente el programa restaurativo, involucramiento parcial del grupo.

La implementación de este panel restaurativo, permitió el acercamiento de la JR entre víctimas y ofensoras condenadas por homicidio, ambas partes fomentaron actitudes de diálogo pacífico, comprensivo y generador de insight. Se concluye que se esbozó un plan de reparación viable aunque no se ha podido implementar completamente por circunstancias personales e institucionales, se considera que esto redunda en el cambio de actitudes y puede prevenir reincidencia. No obstante, ellas siguen privadas de libertad y la valoración de reincidencia fue nula seis meses después, pero esto debería idealmente evaluarse luego de varios años y en situación de libertad.

Aunque todas las internas se implicaron en las actividades, según percepción de la investigadora, hubo dificultades de afrontamiento y transformación en dos internas, casualmente las dos que no realizaron las cartas a las víctimas, ni dicen completamente la verdad a sus hijos, lo que da cuenta del déficit de estrategias de afrontamiento, limitación de su capacidad de reconocimiento de responsabilidad, de reparación y evidencia de su compromiso parcial.

Hubo procesos truncados porque no se logró el diálogo con las víctimas de los casos propios, ya que por razones institucionales trasladaron a las dos mujeres cuyas familias estaban dispuestas. Aunque hubo importantes avances, se reconoce que pueden verse opacados por la permanencia en prisión, que es un lugar negativo para la integración en la sociedad y en el cual se observan que sus políticas de traslado de las internas no tomaron en consideración que ellas estaban participando del programa de justicia restaurativa.

\section{Referencias}

Acosta, D. (2014). Sociología en el penitenciarismo. Prácticas de integración social. Bogotá: Ministerio de Justicia.

Bazemore, G. y Umbreit, M. (2001). A comparison of four restorative conferencing models. Juvenile Justice Bulletin. Recuperado de https://www. ncjrs.gov/pdffiles1/ojjdp/184738.pdf

Beristain, C. M. (2008). Diálogos sobre la reparación. Experiencias en el Sistema Interamericano de Derechos Humanos. Tomo 2. Costa Rica: Instituto Interamericano de Derechos Humanos. https://www.iidh.ed.cr/IIDH/media/1585/dialogos-sobre-la-reparacion-2010.pdf

Cerruti, P. (2009). Procesos emocionales y respuestas punitivas: Acerca del activismo penal de las víctimas del delito. Revista electrónica de psicología política, 7, 15-25 Recuperado de http:// www.psicopol.unsl.edu.ar/agosto09-nota2.pdf

Consejo Nacional de Política Social Conpes 3629 (2009). Sistema de Responsabilidad Penal para Adolescentes: Política de atención al adolescente en conflicto con la ley. Colombia: Departamento Nacional de Planeación. Recuperado de https://www.icbf.gov.co/sites/ default/files/conpes-3629-srpa.pdf 
Corporación AVRE (2009). Manual de buenas prácticas en atención psicojurídica. Bogotá: Unión Europea.

Doolin, K. (2007) But does what it means? Seeking definitional clarity in Restorative Justice. The journal of criminal Law, 71(5), 427-440.

Echeverri, M. y Maca, D. (2007). Justicia restaurativa, contextos marginales y representaciones sociales: algunas ideas sobre la implementación y la aplicación de este tipo de justicia. Recuperado de http://www.justiciarestaurativa.org/news/Articulo\%20JUSTICIA\%20 RESTAURATIVA\%20Colombia.pdf/view

Espinosa, A. y Tapias, A. (2013). Atención a víctimas del conflicto armado interno. Módulo 3 de la serie Atención a Víctimas del Conflicto Armado Interno. Bogotá: Ministerio de Justicia Unión Europea-Universidad San Buenaventura.

European Comission (2010). European best practice of restorative justice in criminal procedu$r e$. Conference publication. Hungary: European Comission Recuperado de https://www.iars. org.uk/sites/default/files/Restorative\%20justice\%20report\%20_\%20Hungary.pdf

Londoño, N., Henao, G., Puerta, I., Posada, S. y Arango, D. (2006). Propiedades psicométricas y validación de la Escala de Estrategias de Coping Modificada (EEC-M) en una Muestra Colombiana. Universitas Psychologica, 5(2), 327-342.

López, W., Pineda, C. y Mullet, E. (2014). El perdón como proceso de transformación hacia la paz. En Ruiz, J. Psicología social y justicia. Bogotá: Universidad Nacional de Colombia.

Movimiento Nacional de Víctimas de Crímenes de Estado (2010). Haciendo memoria en el país del olvido. Bogotá: Procesos editoriales y gráficos. Recuperado de https://nuncamas.movimientodevictimas.org/index.php/producto/ haciendo-memoria-en-el-pais-del-olvido/

Oficina de Programas de Justicia de Estados Unidos (2014). Prácticas prometedoras en justicia restaurativa. Recuperado de: http://www.nij.gov/ nij/toopics/courts/restorative-justice/
Rodríguez, G., Gil, J. y García, E. (1999). Metodología de la investigación cualitativa. Málaga: Ediciones Aljibe.

Ruiz, J. (2014). Miedo al crimen: una revisión de la literatura. En Psicología social y justicia. Bogotá: Universidad Nacional de Colombia.

Sampedro, J. (2010). Las víctimas y el sistema penal. Bogotá: Pontificia Universidad Javeriana.

Sanz, M. (2013) Duelo complicado. Relación de ayuda enfermera (Trabajo de grado) Departamento de enfermería Universidad de Cantabria. Recuperado de: https://repositorio.unican. es/xmlui/bitstream/handle/10902/3130/ SanzGonzalezM.pdf?sequence $=1$

Senado de la República de Colombia. (2006). Ley 1098 de 2006, Ley de Infancia y Adolescencia. Colombia: Legis. Recuperado de https:// www.icbf.gov.co/cargues/avance/docs/ ley_1098_2006.htm

Senado de la República. (2004). Ley 906 de 2004, Código de Procedimiento Penal. Colombia: Legis. Recuperado de http://www.secretariasenado.gov.co/senado/basedoc/ ley_0906_2004.html

Sherman, L. y Strang, H. (2007). Restorative Justice: The Evidence. Bogotá: Legis. Recuperado de http://www.iirp.edu/pdf/RJ_full_report.pdf

Tapias, A. (2015). La justicia restaurativa y sus métodos incluyentes para las víctimas. En Tapias, A. Victimología en América Latina: Enfoque psicojurídico. Bogotá: Ediciones de la $\mathrm{U}$ y Asociación Latinoamericana de Psicología Jurídica y Forense.

Umbreit, M., Vos, B. y Coates, R. (2006). Restorative justice dialogue: evidence-based practice. Center in Support of Restorative Justice Dialogue, Research and Training, 1-16

United Nations (2002). Basic principles on the use of restorative justice programmes in criminal matters. Commission on Crime Prevention and Criminal Justice. Report on the eleventh session Economic and Social Council Official 
Records. New York Supplement, 10, 5-8. Recuperado de http://www.un.org/en/ecosoc/ docs/2002/resolution\%202002-12.pdf

United Nations (2006). Handbook on restorative justice programs. New York: United Nations on Drugs and Crime. Recuperado de http://www.unodc.org/pdf/criminal_justice/06-56290_Ebook.pdf

Uprimny, R., Safon, M., Botero, C. y Restrepo, E. (2006). ¿Justicia transicional sin transición? Verdad, justicia y reparación para Colombia. Bogotá: Centro de Estudios de derecho, Justicia y sociedad. Recuperado de https://www.dejusticia.org/publication/justicia-transicional-sin-transicion-verdad-justiciay-reparacion-para-colombia/

Vaandering, D. (2011). A faithful compass: rethinking restorative justice to find clarity. Contemporary Justice Review, 14(3), 307-328. https://doi.org/10.1080/10282580.2011.589668

Zher, H. (2006). El pequeño libro de la justicia restaurativa. United States of America: Good Books

Zher, H. (2012). Cambiando de lente. Un nuevo enfoque para el crimen y la justicia. Ontario: Herald Press. 